\title{
InTEGRATED HANDS-ON AND REMOTE PID TUNING LABORATORY
}

\author{
Martha Kafuko*, and Tom Wanyama** \\ Department of Mechanical Engineering*, School of Engineering Technology**, McMaster University \\ Hamilton, Ontario \\ kafukom@mcmaster.ca* \\ wanyama@mcmaster.ca**
}

\begin{abstract}
University control engineering courses usually focus on Proportional Integral Derivative (PID) controllers. Moreover PID controllers are used in more than $90 \%$ of the industrial control applications, because they are relatively cheap, easy to use, and robust enough for most industrial applications. However, university teaching attaches most importance to the theoretical knowledge of PID controllers, rather than the practical skills required to support the use of these controllers in industry. In addition, the cost and space challenges associated with hands on laboratories make simulation based laboratories a more attractive option for teaching PID controllers. Unfortunately, simulations do not capture the complexity of control systems that are important to develop the practical skills of students. In this paper, we present a laboratory setup that is used to teach practical skills in PID tuning. The system controls the temperature of a small fictitious house whose temperature is affected by an uncontrolled heating source and blow fan. The PID data is accessible to the system user through OLE( Object Linking \& Embedding) for Process Control, also referred as Open Process Control(OPC) technology. This technology allows the system to be used as a hands-on or remote laboratory, which allows students to learn the complexity of PID controllers, while removing the time and space constraints imposed by purely hands on laboratories. Being accessible remotely, the setup enables and encourages instructors to include demonstrations of PID tuning into their lectures
\end{abstract}

Keywords: Hands on laboratories, simulation based laboratories, remote laboratories, PID tuning, practical skills.

\section{INTRODUCTION}

The Proportional Integral Derivative (PID) controllers are the most widely used controllers in industry because they are relatively cheap, easy to use, and robust. In fact, over $90 \%$ of control systems in industry are based on PID controllers. Consequently, PID controllers are at the center of university control engineering courses. Unfortunately, these courses usually focus more on the theoretical knowledge of PID controllers, and give less attention to the practical skills required to support the use of PID controllers industry.

While PID tuning significantly improves control performance of PID controllers, many times it is not done because it is time consuming and human resource intensive [1]. Moreover, many system integrators lack PID tuning skills, and there are so many tuning methods in literature, which makes it difficult to select appropriate tuning methods for applications. This situation can be improved by strengthening the teaching of PID tuning through hands on learning. However, large student population, limited cost and limited time are major constraints to hands on learning of PID tuning. Universities usually respond to these constraints by using simulations to teach not only PID tuning, but many other important topics of control engineering.

Simulations are cheaper than hands on laboratories, and they remove the time and space constraints imposed by hands on laboratories. However, they are not real, and in many cases they over simplify the problem, narrowing the learning experience to the focus of the laboratory. Hands on laboratories on the other hand give a broad learning experience beyond the main focus of the laboratory. For example our PID tuning laboratory allows students to get an insight into the complexity of the PID loop. Students learn that real PID controlled systems have by far more components that what is shown by the small boxes in simulations. These components may include sensors, signal conditioners, motor drives and Programmable Logic Controllers (PLC). Furthermore, students learn that some in cases, PID controller inputs and/or outputs may be in different locations, warranting communication networks, and causing all sorts of issues.

In this paper we present a laboratory setup for teaching PID tuning. The laboratory is based on the temperature control of a fictitious house. The temperature of the house is affected by a heating source and a disturbing blow fan 
which is randomly switched on and off. Moreover, the system has a PID controlled fan that is used to keep the house temperature to the set value. The laboratory setup data is accessed onsite through a Human Machine Interface (HMI) that is supported by Open Productivity and Control (OPC) technology. This technology allows remotely located students to access the laboratory setup through the Hyper-Text Transfer Protocol (HTTP).

The rest of this paper is arranged as follows: Section 2 covers the motivation for developing our remote access PID tuning laboratory. In Section 3 we present the background to the laboratory and Section 4 deals with the features of the laboratory. The discussion is presented in Section 5 and Section 6 covers the conclusion and future work.

\section{MOTIVATION}

Laboratories are a very important component of learning in science and engineering education [5]. They provide a means for hands on learning, a paradigm that is highly desirable in practising professions such as engineering [3]. However, there many developments that put the future of the traditional practice of hands-on physical laboratories in question. Firstly, university administrators are faced with a number of challenges related to laboratories: Laboratories burden both space and schedules, laboratory equipment is usually expensive, and it needs to be maintained. Secondly, the advancement of digital computer technology has led to the development cheaper simulated laboratories that some educators believe shall replace hands on laboratories [2]. Thirdly, there is a general economically-driven push toward webbased education.

In the teaching of control engineering in general and PID tuning in particular, hands on laboratories shall continue to be the best approach for a long time because of the following reasons:

- Hands on PID tuning laboratories give students an insight into the complexity of the hardware involved in control system. Moreover, students can easily appreciate PID control concepts such as lagging, because they can clearly see that communication network the supports the control system.

- Students know that simulations are not real laboratory equipment and they expect them to work because they are based on some software code. In addition, if the simulation produces unexpected results, students became mistrustful of it [3]. This takes away from the learning experience.

- In control engineering, hands on laboratories give students opportunity to learn soft skills such as following laboratory rules, as well as wiring, interconnecting and configuring laboratory components.

Therefore, we believe that the best way to address laboratory related challenges faced by university administrators, and to ensure that students benefits from hands on learning, is to use hands on laboratories that can also be remotely accessed. Such laboratories allow students to setup laboratory equipment and perform part or all of the laboratory onsite. Thereafter, students can later access the equipment online and continue with the laboratory or tryout the laboratory multiple times to review it. Moreover, they may access the laboratory online to collect data they may have missed when onsite; or they may want to test different PID tuning scenarios and discuss the results with their peers and/or instructors.

\section{BACKGROUND}

Our laboratory equipment for PID tuning utilizes an automated fictitious house presented in the paper titled "A Training Demonstration for Experiential Learning in OPC based Process Automation data Access" [6], as the main component of the plant/process of the PID loop. The house has a heating and cooling system that is controlled using an OPC enabled Programmable Logic Controllers (PLC). In addition, the PLC is the platform on which the PID that controls part of the cooling system is implemented.

\subsection{PID Loop of the Laboratory System}

In the paper titled "Teaching PID and Fuzzy Controllers with LabVIEW", Keller [4] presents a simulated laboratory for teaching PID loop tuning. The simulation is based on the typical block diagram of a feedback control system shown in Figure 1. The figure shows that the control system has two main components, namely: the PID controller and the plant. The error $e(t)$ is the difference between the setpoint $T_{s}(t)$ and the process variable $T_{a}(t)$. The manipulated variable $f(t)$ generated by the PID controller is given by equation 1 . Note that the role of the PID controller is to generate $f(t)$ that minimizes $e(t)$.

$$
f(t)=K_{p} e(t)+K_{i} \int_{0}^{t} e(\tau) d \tau+K_{d} \frac{d}{d t} e(t)
$$

Where:

$K_{p}$ is the proportional gain, or tuning parameter $\mathrm{P}$.

$K_{i}$ is the integral gain or tuning parameter I.

$K_{d}$ is the derivative gain or tuning parameter D.

The simulation of Keller [4] has five functions from which one is selected to represent the plant during 
simulation. While this simple representation of the plant is an effective tool for teaching the theory of PID controllers, it takes away from the reality that sometimes the PLC controller is part of the PID controller, and also part of the plant. This is something that students can easily and clearly experience through hands on PID tuning laboratories. Moreover, hands on labs are able to capture other issues that affect PID tuning such as data communication delay and actuator lag. Yet simulations would require these issue to be separately implemented (simulated), and added to the system.

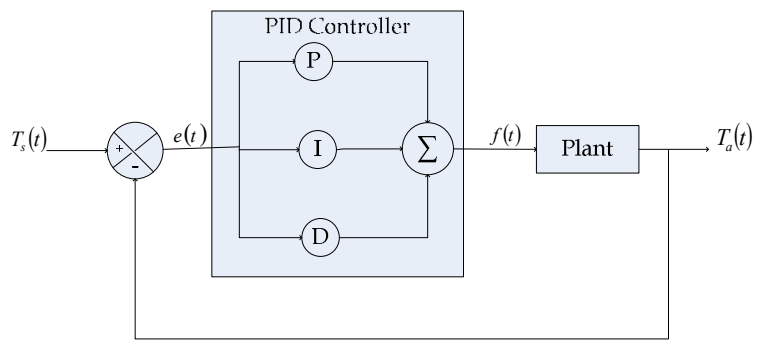

Fig. 1. Block diagram of PID loop.

Figure 2 shows the process diagram of our laboratory system. This is a real PID controlled system in which, unlike in typical PID simulation systems, the plant is different from the process. The setpoint (SP) $T_{s}(t)$ is the desired temperature of the house, and the manipulated variable (MV) $f(t)$ is the $0-5 \mathrm{~V}$ analog input to the KT5194 DC Motor PID speed controller. This controller features two control modes, namely: open loop PWM control, and closed loop PID control. In our laboratory, the controller is used in the open loop PWM control mode, were the $0-5 \mathrm{~V}$ input signal determines the value of the $0-24 \mathrm{~V}$ (10A-maximum) PWM output. The $0-24 \mathrm{~V}$ power supply to the fan DC motor is the control variable (CV) $c(t)$ of our PID loop. The temperature of the fictitious house is measured using an RTD probe whose resistance varies from $100 \Omega$ at $0^{\circ} \mathrm{C}$ to $220 \Omega$ at $300^{\circ} \mathrm{C}$. The RTD signal is fed in a signal conditioner that produces a proportional $0-10 \mathrm{~V}$ analog signal. The signal conditioner output is the input to a Micrologix 1400 PLC that has an ADC the converts the analog signal to $0-4095$ digital variable. This variable is scaled to produce the actual temperature of the house, which is the process variable (PV) $T_{a}(t)$ of the laboratory PID loop.

The plant of the PID loop of our laboratory, and indeed of all real PID loops, is not made up of only the process (house whose temperature is being controlled). But it includes the DC motor controller, DC motor and its fan, heating system, single phase $\mathrm{AC}$ motor and its fan, RTD temperature sensor, signal conditioner, and the Micrologix 1400 PLC, which also generates signals $r(t)$ and $g(t)$ that control the AC fan and the blow heater respectively. In addition, the PLC carries out the analog to digital conversion and the scaling of the temperature measurement signal. Finally, it is important to note that the Micrologix 1400 PLC is also the platform on which the PID controller is implemented. This complexity of system integration is usually not shown by PID loop simulations, and it is one of the reasons we believe that control engineers need to use at least some real laboratories to learn PID loop tuning.

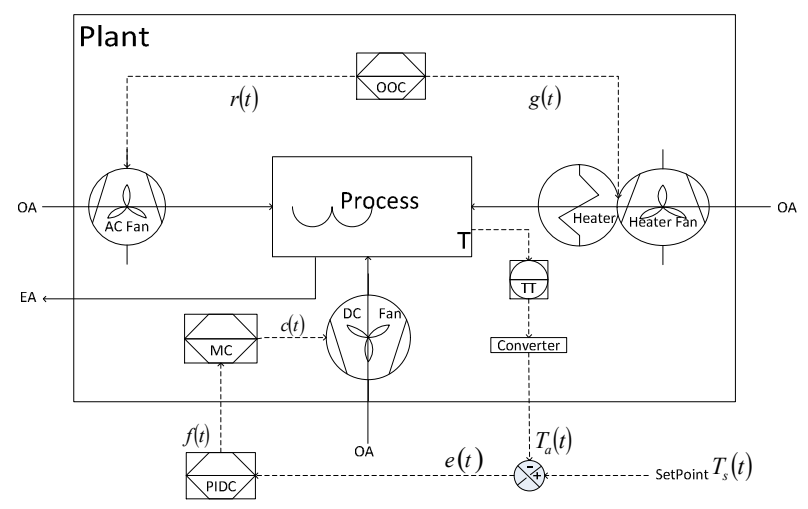

Fig. 2. Process diagram of the PID tuning laboratory.

\subsection{Laboratory Data Access}

Our PID tuning laboratory systems use an OPC enable Allen Bradley Micrologix 1400 PLC. Figure 3 shows how the three types of software interact to support process data access. Firstly, the figure shows that data tags are created in the logic that controls the PID loop.

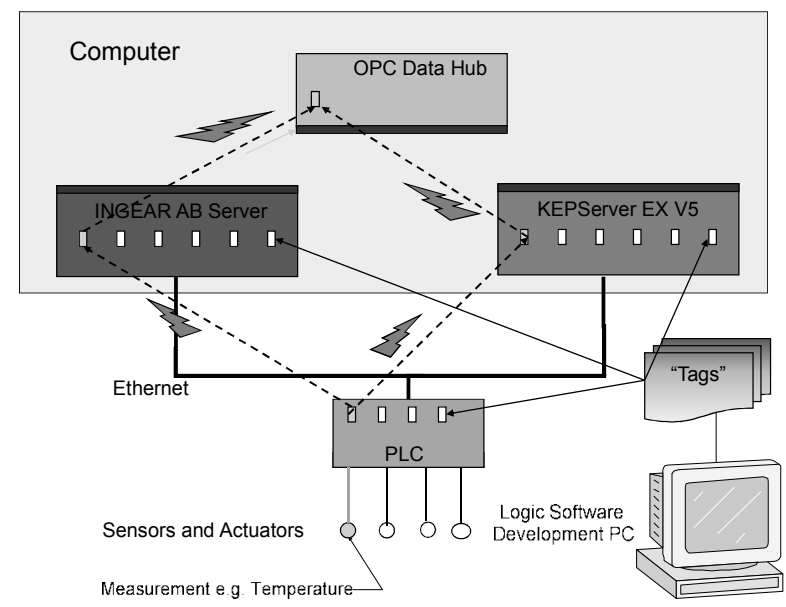

Fig. 3. PID tuning OPC based data access.

When this logic is downloaded onto the PLC, the associated data tags and theirs values are made available to the PLC internal server by the PLC's firmware. 
Secondly, the figure shows that the INGEAR AllenBradley OPC Server accesses the data (tags and their associated values) and makes it available to OPC Client.

OPC servers do not normally poses advanced data access features such as HMI, alarms and event handling, data logging and historian, and process data tunneling and bridging. Therefore, OPC clients are normally utilized to provide these features. In our PID tuning laboratory, we use OPC DataHub [6] to access data from two OPC servers and to implement the Human Machine Interface (HMI) of the laboratory.

\section{PID TUNING LABORATORY}

The laboratory PC and the PLC are connected to an Ethernet router. The router publishes a Wireless Local Area Network (WLAN) that provides access to the control system. Once one logs onto this network, they can change the temperature setting, view temperature inside the fictitious room, switch ON/OFF the lights, change the mode of the heating and cooling system, and switch ON/OFF the heating and cooling systems.

\subsection{Onsite Access to PID Tuning Laboratory}

On site, students can examine the lab equipment and learn hands on the differences between the plant and the process. In this case, they are able to learn that, sometimes the PLC that provides the platform for running the PID controllers can also be part of the plant. In fact, in some PID controllers, industrial communication networks are part of the controlled plant. These cause all sorts of problems for the PID controller, many of which cannot easily be simulated.

After reviewing and understanding the PID temperature control system, students can test it using the HMI shown in Figure 4. The Figure shows that students can adjust the valve of the $\mathrm{P}, \mathrm{I}$ and $\mathrm{D}$ parameters of the PID controller. Moreover, they can change the setpoint temperature, toggle system control mode between PID and $\mathrm{ON} / \mathrm{OFF}$, turn on/off the random fan, and set the maximum heating temperature.

\subsection{Remote Access to PID Tuning Laboratory}

The remote access to the PID tuning laboratory is based on our proposed the McMaster University internet Laboratories (MiLabs) architecture shown in Figure 5. In this architecture, students are authenticated through the existing university Virtual Private Network (VPN), The VPN and the data access software Cogent DataHub allows multiple students to access the laboratory HMI (see Figure 4) through their local web browsers.

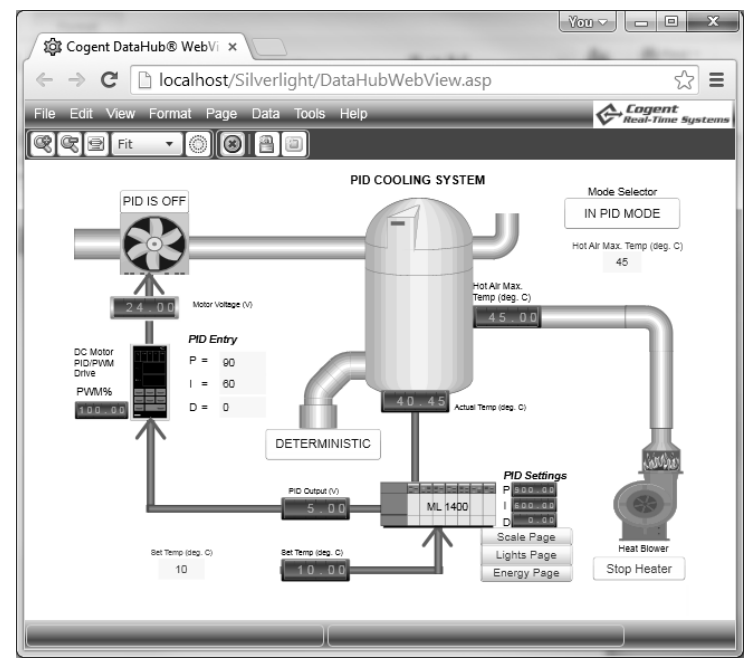

Fig. 4. PID tuning laboratory HMI.

Although multiple students can simultaneously access the laboratory, only one can adjust the setting. This ensures that the system is not randomly adjusted.

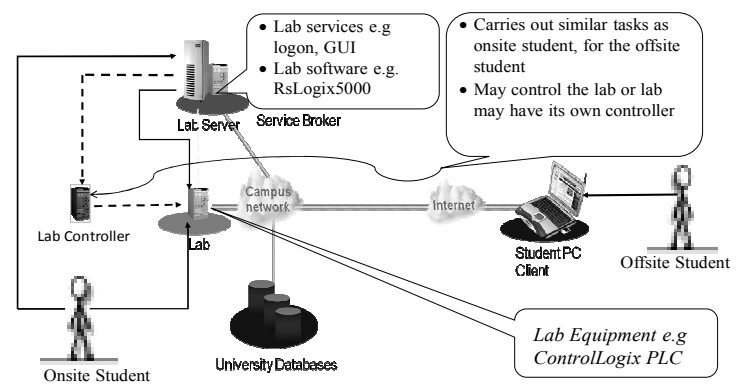

Fig. 5. Proposed McMaster University iLabs (MiLabs) architecture.

The laboratory process data (output) is logged into an excel file on the laboratory computer. Therefore, after the laboratory session, one of the students can retrieve the data and share it with his/her group. Moreover, students can visualize the trend process data in real time using the Cogent DataHub quick trend function (see an example in Figure 6).

\section{DISCUSSION}

Our integrated hands on and remote PID tuning laboratory allows students to learn how PID controlled systems are implemented; generally providing teaching resources for PID systems that cannot easily be simulated. The laboratory also enables students carryout experiments at a time and location of their choosing. This frees up high desired laboratory time and space. In fact, three or four units can be used to provide over a hundred students a 
satisfactory laboratory experiences that combines both theory and practice. Therefopre, we believe that this is one of the most cost effective ways to taking the laboratory to students. Moreover the system can be accessed by instructors who can integrate it into their lectures as a demonstration for the principles of PID controlled systems. Hence, taking the laboratory to the classroom.

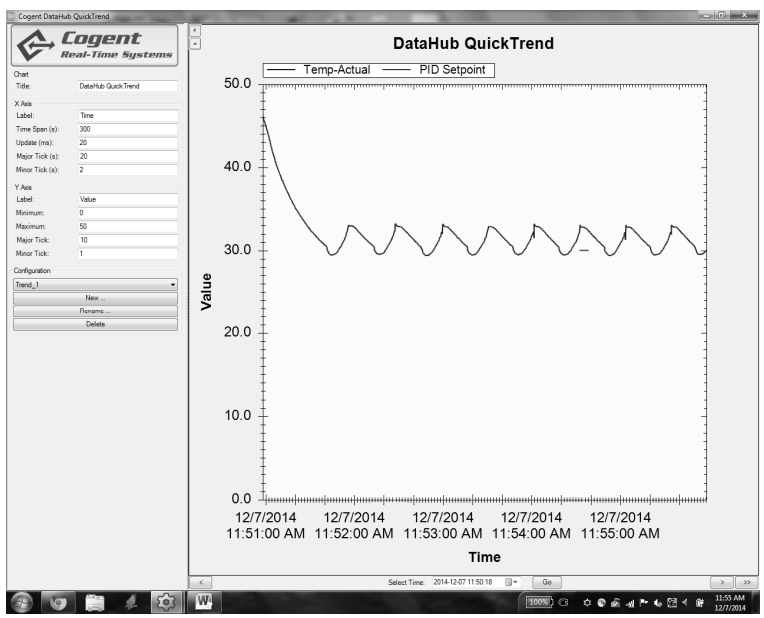

Fig. 6. Example real-time process data visualization.

\section{CONCLUSION AND FUTURE WORK}

If PID controllers are not well tuned, inputs to processes may become unstable, diverging with or without oscillation. This divergence is only limited by saturation or mechanical failure of the system. Moreover, there are so many PID tuning methods in literature which makes it difficult for amateur control engineers to select appropriate methods for their applications. Consequently, we have developed a tool for teaching PID tuning. The tool gives students hands on experience of the intricacies of implementing PID systems. Furthermore, the remote access capability of the laboratory gives students enough time to try out various tuning methods. Moreover, it allows students to tune PID controllers multiple times, reflect on the laboratory, test different PID tuning scenarios, and discuss the results with their peers and/or instructors.

In the future we would like to add a camera and microphone to the laboratory system. This shall allow remotely located students to see the local system HMI, relay status lights, and fans. In addition students shall be able to hear the system fan change speed, and go on and off.

\section{References}

[1] Bohumil Šulc, Stanislav Vrána, "Some Observations on Teaching Practical Controller Tuning Methods in a Laboratory Set-up", In Proc. of the 6th WSEAS International Conference on engineering education, (Stevens Point, Wisconsin, USA), 202 pp., 2009 ISBN: 978-960-474-100-7.

[2] Chris Keller, "Substituting Traditional Hands-On Laboratories with Computer Simulations: What's gained and what's lost?", Physics 4810/7810 Prof. Noah Finkelstein, 13 December 2004, Available as of April $5^{\text {th }}$, 2015

from https://www.google.ca/?gws_rd=ssl\#q=Substituting+Tradit ional+Hands-On+Laboratories+with+Computer+.

[3] James E. Corter, Jeffrey V. Nickerson, Sven K. Esche, And Constantin Chassapis, Seongah Im, Jing Ma, "Constructing Reality: A Study of Remote, Hands-On, and Simulated Laboratories", ACM Transactions on Computer-Human Interaction, Vol. 14, no. 2, Article 7, 2007.

[4] Juerg P. Keller, "Teaching PID and Fuzzy Controllers with LabVIEW", International Journal of Engineering Education, Vol 16, pp. 202-211, 2000. Available as of April $\quad 5^{\text {th }}$, 2015 from http://www.google.ca/url?sa=t\&rct=j\&q=\&esrc=s\&source= web\&cd=2\&ved=0CCQQFjAB\&url=http $\% 3 \mathrm{~A} \% 2 \mathrm{~F} \% 2 \mathrm{Fwe}$ b.fhnw.ch $\% 2$ Fpersonenseiten $\% 2$ Fjuerg.keller $1 \% 2$ Fijee 112 9.pdf\&ei=b8shVY-

qNIWzggSm_IHgBA\&usg=AFQjCNF5cWi5KWWq3GdF 9c_w05ufGqr8dA.

[5] The American Chemical Society, "Importance of Hands-On Laboratory Activities", Public Policy Statement, 20112014. Available as of April $5^{\text {th }}, 2015$ from http:/www.google.ca/url?sa=t\&rct=j\&q=\&esrc=s\&source= web\&cd $=2 \&$ ved $=0$ CCIQFjAB\&url $=\mathrm{http} \% 3 \mathrm{~A} \% 2 \mathrm{~F} \% 2 \mathrm{Fww}$ w.luther.edu $\% 2$ Fmertzecl $\% 2$ Fassets $\% 2$ F 140000 importan ce_of_hands_on_laboratory_activities_ACS_american_che mical_society_2.pdf\&ei=BMghVbz2NcOWNqDrgMgM\& usg=AFQjCNG9zWS5DkVzQo_S47KleGQ3nh4r4A.

[6] Tom Wanyama and Ishwar Singh, "A Training Demonstration for Experiential Learning In OPC Based Process Automation Data Access", in Proc. CEEA Canadian Engineering Education Conf., CEEA2013, (Montreal, Quebec; 17-20 June 2013), 7 pp., 2013. 